\title{
Kyrle's Disease: A Rare Skin Manifestation of Systemic Diseases
}

\author{
ASWINI KUMAR SAHOO, ${ }^{1}$ SUDHASMITA RAUTA ${ }^{2}$
}

\begin{abstract}
A 39-year-old man of diabetic nephropathy presented with pruritic papulo-nodular brown lesions in both arms and legs on extensor surface characterized by central keratin plugs. Lesions were non-tender and numerous, crusted lesions which histologically were perforating disorders, showing features of Kyrle disease. The blood sugar of the patient was kept under control \& hemodialysis was started. Dermatological lesions were treated by Isotretinoin, vitamin A, Tretinoin cream and oral antihistamines.
\end{abstract}

Key-word: CKD, Diabetes Mellitus, Keratin, Kyrle’s Disease.

\section{Case-report}

A-39-years old Hindu male was admitted into Medicine dept. with oliguria. On physical examination he was anemic \& B.P was 180/110 $\mathrm{mm} \mathrm{Hg}$, He was found to have multiple brown papulo-nodular lesions with central keratin plug and silvery scales distributed over the anterior aspect of both thighs and legs (Fig.-1). There were also numerous papules of varying size on the extensor aspect of both elbows (Fig.-2). The lesions were non-tender and associated with severe pruritus. He was a known diabetic for the past 10 years \& on irregular treatment. Necessary investigations (FBS, PPBS, Blood urea, serum creatinine, serum sodium and potassium, USG abdomen) were done \& he was found to have developed diabetic nephropathy (CKD-stage 5). Insulin \& antihypertensive was started to control his blood sugar \& hypertension, subsequently dialysis was done for CKD. The

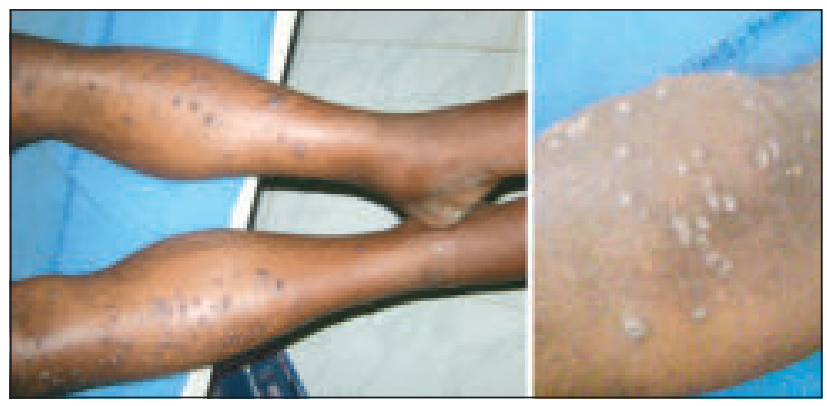

Fig 1: Skin lesion on both lower limbs.

1. Dr. Aswini Kumar Sahoo, Associate Professor, Dept. of Medicine, Maharajah's Institute of Medical Sciences, Vizianagaram, Andhra Pradesh 535217, India.

2. Dr. Sudhasmita Rauta, Asst. Professor, Dept. of Pathology, Maharajah's Institute of Medical Sciences, Vizianagaram, Andhra Pradesh 535217, India.

Correspondence : Dr. Aswini Kumar Sahoo, Associate Professor, Dept. of Medicine, Maharajah's Institute of Medical Sciences, Vizianagaram, Andhra Pradesh 535217, India. E-mail: aks008in@yahoo.co.in

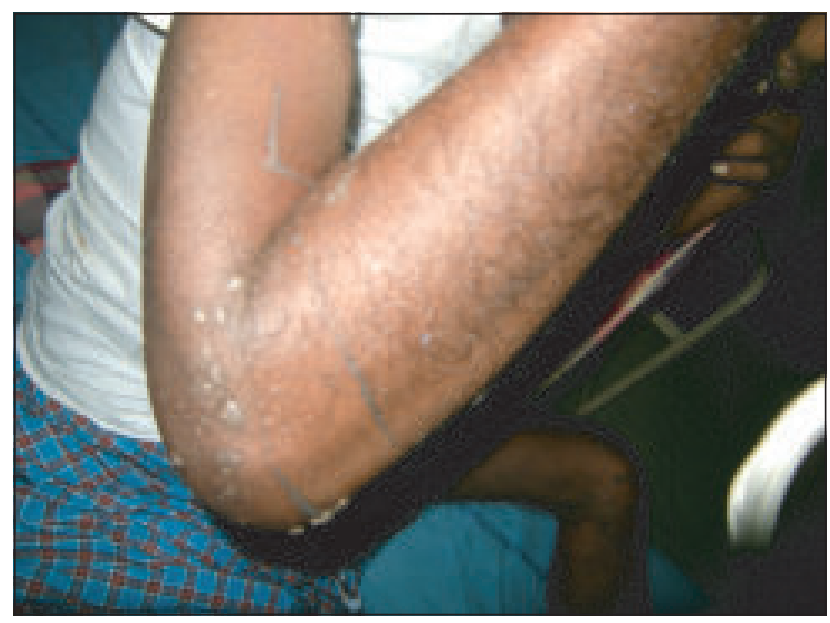

Fig.-2: Skin lesions on elbow.

dermatological lesions were diagnosed to be Kyrle's disease $\&$ treated with Isotretinoin, High dose vitamin A, Tretinoin cream, emollients and oral antihistamines are useful in relieving pruritus.

\section{Discussion}

Kyrle disease was first described in 1916 by Kyrle and is characterized by the formation of large papules with central keratin plugs. ${ }^{1}$ It may be due to metabolic conditions such as uremia ${ }^{1,7}$ especially in patients on dialysis, diabetes mellitus, ${ }^{2,6,7}$ hepatic failure ${ }^{5}$ or as paraneoplastic syndrome in multiple myeloma. ${ }^{3} \mathrm{KD}$ has been also reported with other conditions including tuberculosis, pulmonary aspergillosis, scabies, atopic dermatitis, AIDS, neurodermatitis and malignant and endocrinological disorders. ${ }^{4}$ It can affect both men and women commonly seen in $3^{\text {rd }}$ to $5^{\text {th }}$ decade. Rarely it may be idiopathic or hereditary with autosomal inheritance. Lesions begin as small papules with silvery scales that eventually grow to about $1.5 \mathrm{~cm}$ in diameter to form reddishbrown nodules with a central keratin (horny) plug. Multiple lesions may coalesce to form large keratotic plaques. Lesions occur mostly on the legs but also develop on the arms and in 
the head and neck region. The palms and soles are rarely affected. Without treatment lesions heal spontaneously but new lesions may appear. Lesions are not painful but patients may experience intense pruritus

\section{Conflict of Interest : None}

\section{References}

1. Moss HV. Kyrle's disease. Cutis 1979; 23: 463-6.

2. Harman M, Aytekin S, Akdeniz S et al. Kyrle's disease in diabetes mellitus and chronic renal failure. J Eur Acad Dermatol Venereol 1998; 11: 87-8.

3. Huntley AC. The cutaneous manifestations of diabetes mellitus. J Am Acad Dermatol 1982; 7: 427-4.
4. Detmar M, Ruszczak Z, Imcke E et al. Kyrle disease in juvenile diabetes mellitus and chronic renal failure. $Z$ Hautkr 1990; 65: 53-61.

5. Golusin Z, Poljacki M, Matovic L et al. Kyrle's disease. Med Pregl 2002; 55: 47-50.

6. Kuokkanen K, Niemi KM, Reunala T. Parakeratotic horns in a patient with myeloma. J Cutan Pathol 1987; 14: 54-8.

7. Hinrichs W, Breuckmann F, Altmeyer P et al. Acquired perforating dermatosis: a report on 4 cases associated with scabies infection J Am Acad Dermatol 2004; 51: 665-7. 